\title{
PERCEPCIÓN DE RIESGO DE INFECCIÓN POR VIH ENTRE ADOLESCENTES EMBARAZADAS EN EL DISTRITO FEDERAL DE BRASIL
}

\section{PERCEIVED RISK OF HIV INFECTION AMONG PREGNANT TEENAGERS IN THE FEDERAL DISTRICT OF BRAZIL}

\author{
Kelly Aparecida Palma Alves* \\ Maria do Socorro Nantua Evangelista ${ }^{* *}$
}

\begin{abstract}
RESUMEN
Se trata de un estudio transversal con el objetivo de analizar la percepción de riesgo de la infección por el VIH entre adolescentes embarazadas en el Distrito Federal, Brasil. Fueron entrevistadas 336 adolescentes gestantes de edades comprendidas entre 13 y 19 años, atendidas en el sistema público de salud del Distrito Federal, entre abril y noviembre de 2009. El Comité de Ética aprobó el estudio (Parecer $N^{\circ} 33 / 2009$ ). En el análisis estadístico se utilizó el test $\chi^{2}$. La mayoría de las entrevistadas estaban casadas/unión estable, con una iniciación sexual media de 14,9 años de edad, hicieron uso del preservativo en la primera y última relación sexual un 64,0\% y un $14,9 \%$ respectivamente. El 33,3\% de las adolescentes eran conscientes del riesgo de infección por VIH al quedarse embarazadas, recayendo la mayor percepción de riesgo $(\mathrm{p}=0,014)$ entre las que tuvieron más de un compañero sexual. No se observaron diferencias estadísticas entre la percepción de riesgo y las variables edad, estado civil, cohabitación, escolaridad, religión o frecuencia de uso del preservativo. En conclusión, fue baja la percepción de riesgo de infección por VIH de las adolescentes embarazadas del Distrito Federal.
\end{abstract}

Palabras clave: Adolescencia, riesgo, infecciones por VIH.

\begin{abstract}
This is a transversal study with the aim of analyzing the perception of risk of HIV infection among pregnant adolescents in the Federal District of Brazil. 336 pregnant adolescents between the ages of 13 and 19 who received prenatal care from the public hospital system between April and November 2009 were interviewed. The study was approved by the ethics committee (Opinion No. 33/2009). The Pearson $\chi^{2}$ test was used in the statistical analysis. Most interviewed were married/stable union with sexual initiation average 14.9 years old, made use of condoms in the first and last sexual union $64.0 \%$ and $14.9 \%$ respectively. Around $33.3 \%$ of the adolescents perceived the risk of HIV infection upon becoming pregnant with the highest perception of risk $(\mathrm{p}=0.014)$ among those who had had more than one sexual partner. Statistical differences were not observed with the variables: age, marital status, cohabitation, educational level, religion or frequency of condom use. In conclusion, the perception of risk among pregnant adolescents in the Federal District was low.
\end{abstract}

Key words: Adolescence, risk, HIV infections.

Fecha recepción: 06/02/11 Fecha aceptación: 28/06/12

\footnotetext{
*Enfermera. Secretaría de Estado de Salud del Distrito Federal, Brasil. E-mail: kellyapalves@ig.com.br

${ }^{* *}$ Profesora Universidad de Brasilia y UCB. Brasilia, Distrito Federal, Brasil. E-mail: socorrok@unb.br
} 


\section{INTRODUCCIÓN}

La Organización Mundial de la Salud (1) define la adolescencia como la segunda década de vida del ser humano (de 10 a 19 años). Este intervalo de la vida se caracteriza por un proceso de transición hacia la vida adulta y, en este recorrido, una de las principales transiciones es el aprendizaje sobre la sexualidad, que no se limita a cuestiones biológicas ni, tampoco, a la primera relación sexual. Se trata de un proceso que involucra la familiarización de representaciones, valores, papeles de género, rituales de interacción y de prácticas presentes en la cultura sexual (2).

En general, los adolescentes inician la actividad sexual sin el conocimiento de los padres (3) y como la sexualidad no se encuentra plenamente legitimada, tienen dificultades para discutir el asunto y utilizar protección contra las ITS/VIH y el embarazo. A su vez, la decisión sobre la protección no solo involucra su uso, sino que depende, además, del acceso y manejo de los preservativos que gradualmente se van incorporando al cotidiano del individuo; de la discusión entre las parejas; de la autoconfianza y del apoyo social. Por lo tanto, a pesar de pertinentes, esos aspectos parecen incompatibles con el incipiente aprendizaje sexual durante esa fase de la vida (4).

El uso del preservativo como contraceptivo y la percepción sobre el riesgo de infección por VIH por parte del adolescente están condicionados, especialmente, a la trayectoria de vida, a los valores culturales y al contexto social en que el joven está inserto. Por eso, tanto la percepción individual como la colectiva varía según las creencias, visiones, sensaciones e interpretaciones individuales del grupo poblacional $(5,6)$, esto es, los individuos construyen la propia realidad y evalúan el riesgo según las percepciones subjetivas (7). De este modo, el proceso mental de formación de la percepción de riesgo es complejo, puesto que incluye experiencias que el individuo adquirió a lo largo de su vida (7). Se resalta que la percepción del riesgo de una enfermedad y la adopción de medidas preventivas no se limitan al acceso a informaciones ni a la decisión individual. La comprensión de las diversas prácticas adoptadas frente a la epidemia de SIDA debe plantearse como el resultado de un proceso interactivo y dinámico, construido a partir de la experiencia social y de la visión de mundo de los sujetos (7). Por ello, la transformación del conocimiento en la adopción de prácticas protectoras también se encuentra mediada por una clase social, etnia, cuestiones de género y otros componentes sociales (6).

En el contexto específico de las mujeres, las desigualdades de género pueden traducirse en un aumento de la exposición al riesgo de un embarazo o infección por VIH, en virtud de la dificultad que encuentran para discutir el uso del preservativo con el compañero dada su postura pasiva (falta de poder de decisión), amén de la dependencia emocional, afectiva y financiera (8).

Adicionalmente, los problemas familiares, las presiones grupales, la inexistencia de un proyecto profesional individual, al igual que el deseo de tener hijos, el acceso a la educación y a servicios sanitarios de calidad también influyen, en mayor o menor proporción, en el riesgo de que la adolescente se embarace y/o adquiera el VIH. Por lo tanto, los procesos de aprendizaje de la sexualidad y de la construcción de la autonomía personal pueden tener consecuencias imprevisibles, incluyendo el embarazo (4) y la contaminación por el VIH.

Los números referentes al SIDA en Brasil indican que la epidemia afecta a la población joven de manera diferenciada. Entre 13 y 19 años, los casos son más numerosos entre las mujeres, esto es, el 55,0\% de los 587 casos notificados en 2008 (9). En relación al embarazo en la adolescencia, en 2006 el 21,5\% de los casos en Brasil involucraron a ese grupo, porcentaje que se reduce al 15,5\% en el Distrito Federal (DF) (10). 
Finalmente, se entiende que la eficacia de las medidas preventivas del SIDA y de embarazos entre adolescentes está permeada por el apoyo social que incluye el acceso a la vivienda, a la escuela, a los servicios sanitarios, a la reducción de las desigualdades de género y a las oportunidades de vislumbrar proyectos de vida tanto desde el punto de vista educativo como profesional (2). Considerando, pues, esos presupuestos, el estudio pretende analizar la percepción de riesgo sobre la infección por VIH entre adolescentes embarazadas en el Distrito Federal.

\section{MATERIAL Y MÉTODOS}

Se realizó un estudio transversal con adolescentes entre 13 y 19 años embarazadas, residentes en el Distrito Federal, y atendidas en la consulta prenatal de los servicios públicos de salud, entre abril y noviembre de 2009. Se seleccionaron aleatoriamente 22 servicios de asistencia prenatal de la Secretaría Estadual de Salud (SES/DF). Tres de esas Unidades de Salud tuvieron que ser sustituidas, también por sorteo, por no presentar un registro de atención de adolescentes gestantes objeto de estudio.

La muestra se calculó con datos ofrecidos por la SES/DF sobre el número de nacidos vivos por edad y local de residencia de la gestante adolescente, distribuidos por Regional de Salud de 2005 a 2007. Para el cálculo de la muestra (11) se consideró $\mathrm{a}=5,0 \%$ y d=2,0\%. En resumen, la muestra calculada fue de 336 adolescentes embarazadas, con una media de 15 gestantes por Unidad de Salud.

El instrumento de recolección de datos contenía preguntas respecto a información sociodemográfica, hábitos de vida, comportamiento sexual, así como la percepción de riesgo para la infección por $\mathrm{VIH}$. El instrumento fue sometido a un test previo con adolescentes embarazadas no incluidas en la investigación y aprobado tras ser evaluado.
Las adolescentes embarazadas fueron abordadas para la entrevista en la sala de espera de los centros médicos o en reuniones prenatales en las Unidades de Salud seleccionadas. Se les informó a todas las entrevistadas sobre la investigación y se les invito a participar voluntariamente del estudio. Una vez aceptada la propuesta, firmaron el Término de Consentimiento Informado, documento también firmado por los representantes legales de cada entrevistada, en el caso de menores de 18 años. Para minimizar un posible sesgo de información con relación al comportamiento sexual, las entrevistas se llevaron a cabo cara a cara, realizadas por entrevistadores entrenados y jóvenes (menores de 30 años de edad), en un ambiente privado y con garantía de confidencialidad. Cada entrevista tuvo una duración aproximada de 20 minutos. Este proyecto fue sometido y aprobado por el Comité de Ética de la SES/DF (Parecer No 033/2009). Las informaciones obtenidas fueron organizadas en una base de datos gracias al uso del software SPSS versión 15.0, utilizándose, en el análisis analítico, la prueba chi-cuadrado.

\section{RESULTADOS}

La población del estudio en el Distrito Federal estaba formada por 336 adolescentes embarazadas en las consultas prenatales de las Unidades de Salud Pública en 2009. La media y la mediana de edad fueron de 17,4 y 18,0 años respectivamente. Con relación al estado civil, el 39,6\% del total estaban solteras, el 45,8\% vivían en unión estable y un $14,3 \%$ estaban casadas. Entre las adolescentes con creencia religiosa, esto es, el 85,1\% de las entrevistadas, el 53,0\% eran católicas y el $30,4 \%$ evangélicas. Respecto a la escolaridad, el $59,2 \%$ poseía entre ocho y once años de estudio y el $65,2 \%$ no frecuentaba la escuela en el momento de la entrevista. Tomando en consideración la inserción de las adoles- 
centes gestantes en el mercado de trabajo, se el 68,2\% poseía 2 sueldos mínimos de renta verificó que el 21,7\% del grupo afirmó que (Tabla 1).

tenían una actividad laboral remunerada y Por lo que respecta al estilo de vida de las

Tabla 1. Distribución delas adolescentes embarazadas según características sociodemográficas, Distrito Federal, Brasil, 2009.

\begin{tabular}{|c|c|c|}
\hline Variables & $\mathbf{n}$ & $\%$ \\
\hline \multicolumn{3}{|l|}{ Edad (años) } \\
\hline 13 & 1 & 0,3 \\
\hline 14 & 12 & 3,6 \\
\hline 15 & 23 & 6,8 \\
\hline 16 & 56 & 16,7 \\
\hline 17 & 65 & 19,3 \\
\hline 18 & 73 & 21,7 \\
\hline 19 & 106 & 31,5 \\
\hline \multicolumn{3}{|l|}{ Estado civil } \\
\hline Soltera & 133 & 39,6 \\
\hline Casada & 48 & 14,3 \\
\hline Unión estable & 154 & 45,8 \\
\hline Separada/divorciada & 1 & 0,3 \\
\hline \multicolumn{3}{|l|}{ Religión } \\
\hline Evangélica & 102 & 30,4 \\
\hline Católica & 178 & 53 \\
\hline Ninguna & 50 & 14,9 \\
\hline Otras & 6 & 1,8 \\
\hline \multicolumn{3}{|l|}{ Color/raza } \\
\hline Blanca & 62 & 18,5 \\
\hline Parda & 200 & 59,5 \\
\hline Negra & 59 & 17,6 \\
\hline Otras & 15 & 4,5 \\
\hline Frecuencia escolar & 117 & 34,8 \\
\hline \multicolumn{3}{|l|}{ Escolaridad (años) } \\
\hline Analfabeta & 1 & 0,3 \\
\hline 1 a 3 & 8 & 2,4 \\
\hline 4 a 7 & 110 & 32,7 \\
\hline 8 a 11 & 199 & 59,2 \\
\hline$\geq 12$ & 18 & 5,4 \\
\hline Trabaja & 73 & 21,7 \\
\hline \multicolumn{3}{|c|}{ Renta familiar (sueldos mínimos)* } \\
\hline Menos de 1 & 83 & 24,7 \\
\hline$>1$ a 2 & 146 & 43,5 \\
\hline$>2$ a 5 & 92 & 27,4 \\
\hline$\geq 6$ & 11 & 3,3 \\
\hline Não sabe & 4 & 1,2 \\
\hline
\end{tabular}

gestantes incluidas en esta casuística, más de un $20 \%$ consumía bebidas alcohólicas por lo menos una vez a la semana, un $11,6 \%$ fuma- ba regularmente y un $7,7 \%$ relató el contacto con drogas ilícitas, predominando la marihuana con un $6,0 \%$ de los registros (Tabla 2). 
Tabla 2. Distribución de las adolescentes embarazadas según el estilo de vida, Distrito Federal, Brasil, 2009.

\begin{tabular}{lrr}
\hline Variables & n & $\%$ \\
\hline Consumo de bebidas alcohólicas en los últimos doce meses & & \\
Una vez a la semana & 52 & 15,5 \\
Más de una vez a la semana & 18 & 5,4 \\
Una vez al mes & 42 & 12,5 \\
Menos de una vez al mes & 14 & 4,2 \\
No utilizaron & 210 & 62,5 \\
Uso de tabaco (No cigarrillos/día) & 17 & \\
1 a 4 & 9 & 2,1 \\
5 a 9 & 10 & 3 \\
10 a 19 & 3 & 0,9 \\
$\geq 20$ & 297 & 88,4 \\
No utilizan & & \\
Uso de otras drogas ilícitas en los últimos doce meses & 10 & 3 \\
Sólo marihuana & 4 & 1,2 \\
Sólo cocaína aspirada & 9 & 2,7 \\
Marihuana y cocaína aspirada & 1 & 0,3 \\
Marihuana y crack & 1 & 0,3 \\
Cocaína aspirada y crack & 1 & 0,3 \\
Anfetaminas & 310 & 92,3 \\
No utilizaron &
\end{tabular}

La primera relación sexual se produjo, en promedio, a los 14,8 años. En el primer coito, el $64,0 \%$ de las adolescentes utilizó el preservativo, 30,0\% inició su vida sexual sin protección, un $4,5 \%$ de ellas el anticonceptivo oral, un $0,3 \%$ coito interruptus y el $0,3 \%$ contracepción de emergencia. Al ser cuestionadas sobre los métodos preventivos durante la última relación sexual, el $14,9 \%$ de las gestantes afirmaron el uso del preservativo, el 3,9\% el anticonceptivo oral y el $80,7 \%$ ningún método (Tabla 3 ).

Tabla 3. Características de la primera y de la última relación sexual según informaciones de las adolescentes gestantes en el Distrito Federal - Brasil, 2009.

\begin{tabular}{lrr}
\hline Métodos preventivos utilizados & $\mathbf{n}$ & $\%$ \\
\hline Primera relación sexual & & \\
Preservativo & 215 & 64 \\
ACO $^{*}$ & 15 & 4,5 \\
Coitos interruptus & 1 & 0,3 \\
Contracepción de emergencia & 1 & 0,3 \\
Ningún método & 106 & 31,5 \\
No opinaron & 1 & 0,3 \\
Última relación sexual & & \\
Preservativo & 50 & 14,9 \\
ACO & 13 & 3,9 \\
No opinaron & 2 & 0,6 \\
Ningún método & 271 & 80,7 \\
\hline
\end{tabular}

${ }^{\star}$ ACO: anticonceptivo oral 
Tabla 4. Distribución de los participantes según percepción de riesgo para adquirir el virus VIH al quedarse embarazada, Distrito Federal, DF, Brasil, 2009.

\begin{tabular}{|c|c|c|c|c|}
\hline \multirow{2}{*}{ Características } & \multicolumn{2}{|c|}{$\begin{array}{c}\text { ¿Crees que al quedarte } \\
\text { embarazada has } \\
\text { corrido el riesgo de } \\
\text { contraer el virus VIH? }\end{array}$} & \multirow[b]{2}{*}{$\begin{array}{c}\text { Valor de } \\
\mathrm{p}^{*}\end{array}$} & \multirow[b]{2}{*}{$\begin{array}{c}\text { Tota } \\
\mathbf{n}\end{array}$} \\
\hline & $\begin{array}{c}\text { Sí } \\
\text { n (\%) }\end{array}$ & $\begin{array}{c}\text { No } \\
\text { n (\%) }\end{array}$ & & \\
\hline \multicolumn{5}{|l|}{ Edad } \\
\hline 13 a 17 & $55(35,0)$ & $102(65,0)$ & 0,288 & 157 \\
\hline 18 a 19 & $53(29,6)$ & $126(70,4)$ & & 179 \\
\hline \multicolumn{5}{|l|}{ Estado civil } \\
\hline Soltera & $50(37,9)$ & $82(62,1)$ & 0,08 & 132 \\
\hline Casada/unión de hecho & $58(28,7)$ & $144(71,3)$ & & 202 \\
\hline \multicolumn{5}{|l|}{ Cohabitación } \\
\hline Padre/Madre/Padres & $44(37,9)$ & $72(62,1)$ & 0,111 & 116 \\
\hline Compañero & $56(29,2)$ & $136(70,8)$ & & 192 \\
\hline \multicolumn{5}{|l|}{ Escolaridad (años) } \\
\hline Cero a siete & $44(37,0)$ & $75(63,0)$ & 0,16 & 119 \\
\hline$\geq$ Ocho & $64(29,5)$ & $153(70,5)$ & & 217 \\
\hline \multicolumn{5}{|l|}{ Religión } \\
\hline Católica & $57(32,0)$ & $121(68,0)$ & 0,565 & 101 \\
\hline Evangélica & $29(28,7)$ & $72(71,3)$ & & 178 \\
\hline \multicolumn{5}{|c|}{ No compañeros sexuales en la vida } \\
\hline Uno & $34(24,6)$ & $104(75,4)$ & 0,014 & 138 \\
\hline Dos o más & $74(37,4)$ & $124(62,6)$ & & 198 \\
\hline \multicolumn{5}{|c|}{ Frecuencia del uso del preservativo } \\
\hline Siempre & $20(34,5)$ & $38(65,5)$ & 0,736 & 58 \\
\hline Raramente & $24(36,4)$ & $42(63,6)$ & & 66 \\
\hline A veces & $39(31,7)$ & $84(68,3)$ & & 123 \\
\hline Nunca & $24(27,6)$ & $63(72,4)$ & & 87 \\
\hline
\end{tabular}

${ }^{\star}$ prueba chi-cuadrado

Entre aquellas que hacían uso del preservativo, un $17,3 \%$ relató usar el preservativo "siempre", el 45,8\% definió su uso como "raramente o nunca" y el 36,6\% afirmó usar ese método preventivo "a veces". Hubo un registro, en promedio, de 2,76 compañeros sexuales por entrevistada, existiendo un 41,0\% que relató haber tenido un único compañero en su vida.

Al embarazarse, el 33,3\% de las gestantes se dio cuenta del riesgo de adquirir la infección por VIH. Las razones para considerarse en situación de riesgo fueron predominante la no utilización del preservativo en la relación sexual $(39,3 \%)$, seguida por la facilidad de contaminación por el VIH $(23,1 \%)$, la desconfianza y el desconocimiento del perfil viral del compañero, con un 10,0\% y un $6,2 \%$ respectivamente. Otros motivos fueron: la ruptura del preservativo $(2,7 \%)$, la no realización de la prueba anti VIH por parte del compañero $(1,8 \%)$ y el $15,1 \%$ no supo explicar los motivos.

Según la visión de 224 entrevistadas que no se dieron cuenta del riesgo de infección VIH al embarazarse, las explicaciones para la presunta protección fueron: confianza en el compañero $(44,6 \%)$, el compañero era sano $(14,6 \%)$, tenía un único compañero fijo $(6,2 \%)$, la serología era negativa para VIH 
(7,8\%), utilizaba eventualmente el preservativo $(2,7 \%)$, era la primera relación sexual de la pareja $(1,3 \%)$ y no contestaron a esta pregunta $(22,8 \%)$.

Una percepción mayor de riesgo de contaminación por el virus VIH $(35,0 \%)$ se observó entre las gestantes con edades entre 13 y 17 años al ser comparadas con las de 18 y 19 años $(29,6 \%)$. Sin embargo, la diferencia no fue estadísticamente significativa $(\mathrm{p}=0,288)$. En lo referente al estado civil, hubo un mayor porcentaje de solteras con mayor percepción de riesgo (37,9\%) que las casadas/unión estable $(\mathrm{p}=0,080)$. Por otra parte, las adolescentes que residían con los padres $(37,9 \%)$ sintieron más el riesgo de la infección por el HIV que aquellas que residían con el compañero $(\mathrm{p}=0,111)$. Las gestantes adolescentes con una media de siete años de estudio tuvieron una percepción mayor del riesgo de adquirir la infección por VIH $(37,0 \%)$ que las demás, aunque sin asociación estadística $(\mathrm{p}=0,160)$.

Hubo un mayor número de adolescentes católicas con percepción de riesgo a la infección VIH (32,0\%), si se comparan a las evangélicas $(28,7 \%)$, sin diferencia estadística significativa $(\mathrm{p}=0,565)$. Gestantes con más de dos compañeros sexuales a lo largo de su vida no tenían una mayor percepción de riesgo de contaminación por VIH al quedarse embarazadas, si las comparamos con aquellas que declararon más de dos compañeros sexuales en su vida, con asociación estadística significativa $(\mathrm{p}=0,014)$. Adolescentes con relatos de uso de preservativo "raramente" sintieron un mayor riesgo de adquirir el virus VIH $(36,4 \%)$ en relación a los demás grupos, sin significancia estadística $(\mathrm{p}=0,429)$.

\section{DISCUSIÓN Y CONCLUSIÓN}

En lo referente a la edad, se pudo observar que el embarazo fue más frecuente entre las adolescentes de 18 y 19 años (53,2\%); esto es, después de haber adquirido la mayoría de edad civil, corroborando con otros estudios sobre embarazo en la adolescencia $(2,12)$.

Considerando el estado civil, la mayor parte de las adolescentes declaró estar casada o en unión estable. Un estudio realizado en una maternidad de Teresina/PI en 2004 mostró que un $69,1 \%$ de las adolescentes con antecedentes gestacionales estaban casadas y o en unión estable (13). En un estudio domiciliar realizado en 2005 con adolescentes de Ribeirão Preto/SP, se verificó que el 80,0\% estaban solteras (14). Los hallazgos de Bergamim et al. (15), en una encuesta domiciliar con adolescentes no gestantes en la zona oeste de São Paulo en 2007, registraron un $93,8 \%$ de participantes solteras. Los estudios retratan un escenario en el que predominan las casadas y/o en unión estable, al tratarse de adolescentes embarazadas, coincidiendo con los resultados de la encuesta relatada. Sin embargo, en las encuestas realizadas con adolescentes no embarazadas, predominan las solteras. Según autores $(16,17)$ la presión social debido al embarazo favorece la formalización de una unión, lo que se refleja, de manera formal o informal, en el estado civil. Es necesario hacer hincapié en que tanto la unión consensual como los matrimonios son eventos importantes en la trayectoria afectivo-sexual del individuo y representan un marco en el proceso de autonomía de los adolescentes con relación a su familia de origen, especialmente cuando no existen otros recursos/proyectos de vida (2).

En esta casuística predominaron adolescentes de religión católica, seguidas de evangélicas y de las que se denominaron sin religión. Un estudio realizado en 2008 en João Pessoa/PB mostró que el 50,0\% de los adolescentes de ambos sexos entre 13 y 18 años, estudiando en escuelas públicas y privadas eran católicos y un 18,0\% evangélicos (18), corroborando los resultados de la presente investigación. Es importante recordar que la creencia religiosa implica la presencia de una orden moral, con padrones de conducta con- 
siderados rígidos, donde cada religión desarrolla modos específicos de orientar comportamientos y de disciplinar a sus seguidores. No obstante, parece que esas orientaciones han tenido un impacto relativamente bajo en el comportamiento sexual de las adolescentes, ya que la religión se considera herencia familiar, lo que significa tan sólo que el adolescente se socializó mediante la moral compartida por el núcleo familiar (19). Por otra parte, las orientaciones espirituales emitidas por la familia de las adolescentes no determinan la adhesión ni la aceptación de esos preceptos religiosos. Ese es el caso de la posición oficial de la Iglesia Católica, que se muestra contraria al uso del preservativo y del sexo antes del matrimonio, contrastando con el resultado obtenido en este estudio, que revela la presencia de adolescentes embarazadas viviendo en unión consensuada o permaneciendo solteras.

Un índice significativo de adolescentes embarazadas $(62,0 \%)$ no frecuentaba la escuela, aunque no fue posible afirmar que la evasión escolar haya sido motivada por la gestación, resultado semejante al obtenido por Ximenes Neto et al. (20) en 2003 en Ceará, con adolescentes embarazadas. Según Heilborn et al. (2), en las clases populares las trayectorias escolares femeninas son discontinuas y presentan desfases de edad, de curso e interrupciones que, en innúmeras ocasiones, anteceden al embarazo. Las enormes disparidades económicas, sociales y culturales existentes en Brasil influyen directamente en el embarazo adolescente. De igual manera, cuando el embarazo se produce antes de finalizar los estudios, o antes de la inserción en el mercado de trabajo se produce una interrupción en la secuencia de eventos esperados socialmente para la juventud, lo que connota un problema social. Se debe considerar, sin embargo, que el embarazo puede ser el resultado de un proceso de elección en el que muchas veces la maternidad parece ser un proyecto social y de vida de muchas adolescentes cuyos planes educativos y profesio- nales difícilmente se podrían concretizar (2).

En lo referente a la escolaridad, la mayoría de las entrevistadas contaba con más de ocho años de estudio. Una encuesta realizada con adolescentes residentes en Vitoria/ES, en 2002, reveló que gran parte de esa población cursaba la enseñanza media (21). Según datos obtenidos en 2008 en la Pesquisa Nacional por Amostra de Domicílios (PNAD) (22), los adolescentes de la región CentroOeste tenían una media de 7,1 años de estudio. Por lo tanto, las adolescentes de este estudio reflejaron el perfil de escolaridad de la región.

La gran mayoría de las entrevistadas poseían una renta familiar de unos dos sueldos mínimos y el 78,3\% de ellas no trabajaban. De acuerdo con PNAD (22), cerca de un tercio de las familias de la región Centro-Oeste poseía una renta de, aproximadamente, dos sueldos mínimos, coincidiendo con el perfil social de las adolescentes embarazadas estudiadas. La situación económica desfavorable de las familias de esas adolescentes también corrobora la asociación entre el embarazo en la adolescencia y el bajo nivel socioeconómico (16). Además, esas adolescentes probablemente tendrán que enfrentar el trabajo para mantener al bebé, lo que, a su vez, podrá inviabilizar la continuidad de los estudios. Adicionalmente, la dependencia financiera influye en el poder de decisión de las relaciones sexuales de la adolescente, en lo referente a la negociación sobre el uso del preservativo (23) y su compra (8), entre otros obstáculos.

Las adolescentes confesaron el uso de alcohol, tabaco y drogas ilícitas, especialmente de la marihuana. Un estudio multicéntrico relatado por Bertoni et al. (24), realizado en colegios públicos y municipales de Minas Gerais (Brasil) con adolescentes no embarazadas entre 15 y 19 años, mostró que el $34,2 \%$, el $8,8 \%$ y el $4,7 \%$ de ellas ya habían hecho uso del alcohol, tabaco y marihuana, respectivamente. Chalem et al. (16) observaron idénticos resultados entre adolescentes embarazadas en São Paulo (Brasil), esto es, 
el consumo de tabaco (17,3\%), de alcohol $(26,6 \%)$ y de marihuana $(1,7 \%)$. El consumo de drogas, legales o ilegales, está presente en la vida de los adolescentes, independientemente del contexto y de la región del país, incluyendo embarazadas y no embarazadas.

La edad media de iniciación sexual en este estudio se situó en 14,9 años, resultado semejante al estudio realizado con adolescentes embarazadas en Marília/SP (14,7 años) (25). En Colombia y Texas (EE. UU.) la media de edad de iniciación sexual registrada entre las mujeres fue de 14,0 y 14,8 años, repectivamente $(26,27)$. Por consiguiente, diferentes estudios con adolescentes, embarazadas o no, presentaron resultados similares al del Distrito Federal, corroborando la tendencia de anticipación del inicio de la vida sexual por parte de las adolescentes $(14,15,26,28)$. Experiencias realizadas en los Estados Unidos revelaron que la educación sexual -en el currículo de la educación formal de los adolescentes ante la primera relación sexualestaba asociada a la postergación del primer coito y a un aumento en el uso de medidas protectoras (29). En ese sentido, el resultado sugiere que ese componente curricular puede ser un aliado importante en la discusión del uso de la protección y en la autonomía de adolescentes frente al VIH y al embarazo.

En esta casuística se produjo una reducción del uso del preservativo desde la primera relación sexual hasta el último contacto. En la primera relación, el preservativo fue predominante en un $64,0 \%$ de los casos $y$, en el último coito, en menos del 15,0\%. En 2005 un estudio del Programa Nacional de ITS/SIDA reveló que un $62,5 \%$ de las adolescentes (entre 16 y 19 años) afirmaron que usaron el preservativo en su primera relación sexual (30). En Ribeirão Preto/SP, en 2005, el $71,1 \%$ de las adolescentes también utilizó el preservativo en su primer contacto sexual y el $37,1 \%$ durante el último coito (14). Otros estudios $(18,31)$, también presentaron resultados similares.

Datos de la bibliografía médica también indican que hay una mayor adhesión al uso del preservativo durante la primera relación sexual cuando el compañero es "desconocido", esto es, la utilización del preservativo asociado a la noción de riesgo, sin la incorporación de esa práctica preventiva regular en relaciones estables. En relaciones con un compañero fijo el uso del preservativo depende de una negociación y discusión entre la pareja; esa capacidad de negociación se adquiere socialmente y está vinculada a las cuestiones de género y a las posibilidades culturales de elección de determinadas conductas $(2,7)$.

Más de una cuarta parte de las entrevistadas declararon baja frecuencia en el uso del preservativo de forma consistente. En una encuesta domiciliar realizada en Ribeirão Preto/SP en 2005, un 35,2\% de las adolescentes lo utilizaron como protección en todas sus relaciones sexuales y un $25,9 \%$ nunca había hecho uso del preservativo (14). Un estudio transversal realizado en 2002 en Vitoria/ ES registró que el 23,4\% de las adolescentes utilizaba preservativos de forma consistente $y$, un $14,1 \%$ no los utilizaba nunca (21). En resumen, incluso con la implementación de la educación sexual en las escuelas, es relativamente baja la frecuencia del uso consistente del preservativo entre las adolescentes en los distintos estudios. Ante tales resultados es necesario cuestionarse: ¿Cómo lograr que el adolescente cambie ese comportamiento ante la ITS/SIDA y el embarazo?

El uso consistente del preservativo por parte de las mujeres durante la adolescencia es problemático, ya que las relaciones sexuales ocurren, generalmente, sin el conocimiento de los padres, dificultando la práctica de mantener siempre el preservativo con sus pertenencias, transfiriéndole al compañero la responsabilidad por la protección (32). A su vez, incluso con el acceso y la intención de utilizar el preservativo, muchas de ellas son vistas con desconfianza por el compañero, que interpreta la precaución como una señal de infidelidad. Y en esa coyuntura emergen 
las asimetrías de género (8) y la sumisión femenina, limitando el poder de negociación de las mujeres en las relaciones sexuales y, por consiguiente, donde reposan las dificultades de protección efectiva contra las ITS, la infección por el VIH y el embarazo $(8,15)$.

En este contexto, un tercio de las adolescentes del estudio se consideró susceptible de adquirir el virus VIH al quedarse embarazada. Doreto et al. (14) encontró una percepción de riesgo del 65,0\% en 2005 en Ribeirão Preto/SP. Esa situación revela la pertinencia de repensar los programas de educación sexual existentes, tanto en el colegio como en los medios de comunicación o en los centros de salud, ante lo cual cabe preguntarse ¿Cuál es la contribución de tales abordajes y qué reflexiones aportan al contexto de los adolescentes ante el ejercicio de su sexualidad?

La no utilización del preservativo provocó que parte de las embarazadas llegasen a considerarse en situación de riesgo de adquirir el VIH. Por una parte, eso significó que la comprensión de la prevención de la infección por VIH con el uso del preservativo se halla incorporada en el imaginario de las entrevistadas. Sin embargo, no se observó la adopción de un comportamiento protector apropiado para identificar, en las adolescentes, su capacidad autónoma como mujer y ciudadana, frente a una situación de riesgo.

Entre las adolescentes que no percibieron el riesgo de infección por $\mathrm{VIH}$, la mayoría afirmó que "confiaba en su pareja", principal razón que el estudio de Doreto et al. (14) relacionó como responsable por la no percepción de riesgo. Se puede resaltar que los datos de la epidemia del SIDA evidenció un aumento del número de casos entre mujeres con compañeros fijos (15), en función de la asociación entre la relación afectiva y la seguridad de la protección (8). Esa postura femenina guarda estrecha relación con el enfoque del cambio de comportamiento individual conferido por las acciones educativas que desconsideran que las relaciones se producen en contextos interpersonales (2), y esos, al mismo tiempo, son influidos por otras representaciones de la sexualidad.

En este estudio, la relación entre la percepción del riesgo y la edad mostró que las adolescentes con edades comprendidas entre 13 y 17 años fueron quienes más consideraron la posibilidad de adquirir la infección por VIH. Probablemente, la diferencia entre los grupos de mayor edad puede estar relacionada al hecho de que las adolescentes más jóvenes hayan recibido más informaciones a través de los medios de comunicación o, incluso, la propia escuela. A su vez, la iniciación sexual cada vez más precoz hace necesaria la necesidad de acceso a las informaciones a una edad más temprana, corroborando la pertinencia del abordaje de este tema en la escuela que suele tratarse alrededor de los 13 años (26).

La menor percepción de riesgo de adquirir la infección por VIH se encontró entre las adolescentes casadas/unión estable. En 2001, un estudio realizado con jóvenes entre 15 y 24 años en Mozambique reveló que las mujeres solteras consideraron más el riesgo de infección VIH al compararlas a las casadas (33). Posiblemente, tener pareja fija induce a una falsa ilusión de protección, ya que existe una relación afectiva y confianza en la presunta fidelidad de la pareja, provocando un cierto alivio de las medidas de protección. Praça et al. (34) señalaron que, generalmente, la mujer cree en el sentido de responsabilidad de su compañero para que su familia y ella se mantengan sanas. En definitiva, les falta poder para discutir sobre el SIDA en el contexto de una relación "estable" ya que el tema puede generar cuestionamientos en la relación afectiva con su pareja (14). Por ello, puede ser aún más difícil para las adolescentes que están adquiriendo esa habilidad de negociación con su pareja.

En esta investigación, las participantes con un máximo de siete años de escolaridad tuvieron una mayor conciencia del riesgo de 
adquirir la infección por VIH, si las comparamos a las más escolarizadas (más de ocho años de estudios), discrepando del referencial teórico presentado (35). Sin embargo, los autores sugirieron que el mayor poder adquisitivo, el elevado grado de instrucción y la independencia financiera de las mujeres no supone un mayor espacio de negociación en las relaciones con su actual pareja, sintiéndose menos expuestas al riesgo (15).

Llevando en consideración la religión, las adolescentes católicas tuvieron una mayor percepción del riesgo de adquirir el virus VIH al quedarse embarazadas. En una investigación cualitativa realizada en São Paulo, en 2007, con hombres y mujeres entre 15 y 23 años, los católicos dieron muestras de una convivencia con la tradición religiosa sin participación afectiva en los rituales religiosos, en las orientaciones y actividades de la comunidad (19). Esa flexibilidad de los jóvenes podría haber actuado como facilitador de posiciones independientes de la moral católica, como en el caso del uso del preservativo (la iglesia no recomienda su uso), hecho que parece haber contribuido a una mayor percepción del riesgo sobre el VIH.

Se constató, incluso, una mayor percepción de riesgo de la infección VIH entre las adolescentes con más de un compañero. Un estudio realizado con adolescentes de ambos sexos de la enseñanza media de Santa Catarina, en 2002, mostró que personas con más de un compañero sexual se sintieron más expuestas al riesgo de adquirir la infección por VIH (36). Una investigación realizada en la República de Zambia en 2007, reveló que la percepción de riesgo fue mayor entre las mujeres con más de un compañero (37). Aunque esos estudios hayan hecho uso de muestras y metodologías diferentes, ambos registraron la misma tendencia del presente estudio, que fue el reducido porcentaje de uso del preservativo, pese a una mayor percepción de riesgo. Esos resultados nos alertan sobre la necesidad de un abordaje educa- tivo que problematice el uso del preservativo no sólo bajo un enfoque biológico, sino que considere los contextos y trayectorias de vida $(6,7)$ de los jóvenes.

Las adolescentes que "raramente" utilizaron el preservativo fueron las que se dieron cuenta del riesgo de adquirir la infección por VIH. Probablemente, muchas de esas adolescentes no sólo tenían dificultades de negociación con el compañero en lo referente a la decisión del uso de protección (23), sino también de acceso a los preservativos, entre otras formas de protección. Parece evidente que otros componentes están involucrados en la toma de decisión en lo que respecta al uso del preservativo, que van más allá del conocimiento del método, involucrando procesos de aprendizaje de la sexualidad que las acciones de educación sexual aún necesitan discutir con los adolescentes.

En conclusión, los resultados del estudio demuestran que varios factores están involucrados en la percepción de riesgo de la infección por VIH entre las adolescentes gestantes en el Distrito Federal. Tal percepción debe analizarse en un contexto de aprendizaje de la sexualidad fuertemente influido por cuestiones de género y de clases sociales, que se van conformando en la construcción de diferentes trayectorias de vida. Se debe destacar que la complejidad y la relevancia del tema exigen políticas públicas amplias en las áreas de sanidad, trabajo, educación y ocio, especialmente destinadas al grupo, con el fin de que, cada vez más, una parte de esa población empiece a usar el preservativo de forma consistente como forma de prevenir, no sólo el embarazo, sino también la trasmisión de las ITS/VIH/SIDA. Para ello, las acciones educativas del sector salud y de la escuela se deben basar en la autonomía de las adolescentes como estrategia para la reducción de la desigualdad de género, confiriéndoles poder y estimulándolas en la búsqueda permanente de valores para la construcción de la ciudadanía. 


\section{REFERENCIAS}

1. World Health Organization. Aider les jeunes a faire des choix sains en matière de sexualité et de procriation, déclare le directeur général de l'OMS. Genève: World Health Organization; 1999.

2. Heilborn ML, Aquino EML, Bozon M, Knauth D et al. O aprendizado da sexualidade: reprodução e trajetórias sociais de jovens brasileiros. Rio de Janeiro: Fiocruz/Garamond; 2006.

3. Brandão ER. Desafios da contracepção juvenil: interseções entre gênero, sexualidade e saúde. Cien Saude Colet. 2009; 14(4):1063-71.

4. Brandão ER, Heilborn ML. Sexualidade e gravidez na adolescência entre jovens de camadas médias do Rio de Janeiro, Brasil. Cad Saude Publica. 2006; 22(7): 1421-30.

5. Peres F. Onde mora o perigo? Percepção de riscos, ambiente e saúde. En: Minayo De Souza MC, Carvalho de Miranda A, editores. Saúde e ambiente sustentável: estreitando nós. Rio de Janeiro: Fiocruz; 2002. p.135-42.

6. Paicheler G. General population and HIV prevention: from risk to action. Cad Saude Publica. 1999; 15 (Suppl 2): 93-105.

7. Monteiro S. Aids, sexualidade e gênero: a lógica da proteção entre jovens de um bairro popular carioca [Tese de doutorado]. [Rio de Janeiro]: Escola Nacional de Saúde Pública, Fundação Oswaldo Cruz; 1999.

8. Guilhem D. Escravas do risco: bioética, mulheres e aids. Brasília: Editora Universidade de Brasília: Finatec; 2005.

9. Ministério da Saúde Brasil. Boletim epidemiológico: AIDS. Ano VI no 1 julho a dezembro de 2008/janeiro a junho de 2009. Brasília: Ministério da Saúde; 2009.
10. Ministério da Saúde Brasil. Informações de saúde: Estatísticas vitais 2006. [Internet]. 2006 [actualizado 2008; citado 18 mar 2010]. Disponible en: http://www2. datasus.gov.br

11. Daniel WW. Biostatistics: a foundation for analysis in the health sciences. New York: John Wiley and Sons Inc; 1974.

12. Heilborn ML, Bozon M, Aquino EML, Knauth D, Rohden F, Cabral CS. Trajetórias sexuais de jovens brasileiros: da iniciação a uma possível gravidez. En: Ministério da Saúde, ed. Um olhar sobre o jovem no Brasil. Série B. Textos básicos em saúde. Brasília: Fiocruz; 2008. p.4560.

13. Sousa MCR, Gomes KRO. Conhecimento objetivo e percebido sobre contraceptivos hormonais orais entre adolescentes com antecedentes gestacionais. Cad. Saude Publica. 2009; 25(3): 645-54.

14 Doreto DT, Vieira EM. O conhecimento sobre doenças sexualmente transmissíveis entre adolescentes de baixa renda em Ribeirão Preto, São Paulo, Brasil. Cad Saude Publica. 2007; 23(10): 2511-16.

15. Bergamim MD, Borges ALV. Fatores associados à iniciação sexual entre adolescentes da zona oeste do município de São Paulo. Rev Gaucha Enferm. 2009; 30(3):420-8.

16. Chalem E, Mitsuhiro SS, Ferri CP, Barros MCM, Guinsburg R et al. Gravidez na adolescência: perfil sóciodemográfico e comportamental de uma população da periferia de São Paulo, Brasil. Cad Saude Pública. 2007; 23(1): 177-86.

17. Bruno ZV, Feitosa FEL, Silveira KP, Morais IQ, Bezerra MF. Reincidência de gravidez em adolescentes. Rev Bras Ginecol Obstet. 2009; 31(10): 480-4.

18. Saldanha AAW, Carvalho EAB, Diniz RF, Freitas ES, Félix SMF et al. Comportamento sexual e vulnerabilidade à aids: um estudo descrito com perspectiva de práticas de prevenção DST. DST-J Bras 
Doenças Sex Transm. 2008; 20(1): 36-44.

19. Silva CG, Santos AO, Licciardi DC, Paiva V. Religiosidade, juventude e sexualidade: entre a autonomia e a rigidez. Psicol Estud. 2008; 13(4):683-69.

20. Ximenes Neto FRG, Dias MSA, Rocha J, Cunha ICKO. Gravidez na adolescência: motivos e percepções de adolescentes. Rev Bras Enferm. 2007; 60(3): 279-85.

21. Miranda AE, Gadelha AMJ, Szwarcwald CL. Padrão de comportamento relacionado às práticas sexuais e ao uso de drogas de adolescentes do sexo feminino residentes em Vitória, Espírito Santo, Brasil, 2002. Cad Saude Pública. 2005; 21(1): 207-16.

22. Instituto Brasileiro de Geografia e Estatística. Pesquisa Nacional por Amostra de Domicílios. Síntese de indicadores 2008. [Internet]. 2008 [actualizado 2010; citado 19 abril 2010]. Disponible en: http://www.ibge.gov.br

23. Evangelista MSN, Madalena M, Tavares LL, Azevedo AMF, Fonseca NV. Percepción del riesgo de la infección VIH entre hombres y mujeres con infecciones de transmisión sexual. Cienc enferm. 2007; XIII (1):69-80.

24. Bertoni N, Bastos FI, Mello MB, Makuch MY, Sousa MH, et al. Uso de álcool e drogas e sua influência sobre as práticas sexuais de adolescentes de Minas Gerais, Brasil. Cad Saude Pública. 2009; 25(6): 1350-60.

25. Caputo VG, Bordin IA. Gravidez na adolescência e uso freqüente de álcool e drogas no contexto familiar. Rev Saude Publica. 2008; 42(3):402-10.

26. González JC. Conocimientos, actitudes y prácticas sobre la sexualidad en una población adolescente escolar. Rev Saude Publica. 2009; 11(1):14-26.

27. Auslander BA, Perfect MM, Succop PA, Rosenthal SL. Perceptions of sexual assertiveness among adolescents girls: initiation, refusal and use of protective be- haviors. J Pediatr Adolesc Gynecol. 2007; 20(3): 157-62.

28. Borges ALV, Latorre MRDO, Schor N. Fatores associados ao início da vida sexual de adolescentes matriculados em uma unidade de saúde da família da zona leste do município de São Paulo, Brasil. Cad Saude Pública. 2007; 23(7): 1583-94.

29. Mueller TE, Gavin LE, Kulkarni A. The association between sex education and youth's engagement in sexual intercourse, age at first intercourse, and birth control use at first sex. J Adolesc Health. 2008; 42(1):89-96.

30. Paiva V, Pupo LR, Barboza R. O direito à prevenção e os desafios da redução da vulnerabilidade ao HIV no Brasil. Rev Saude Publica. 2006; 40 Suppl: 109-19.

31. Teixeira AMFB, Knauth DR, Fachel JMG, Leal AF. Adolescentes e uso de preservativos: as escolhas dos jovens de três capitais brasileiras na iniciação e na última relação sexual. Cad Saude Pública 2006; 22(7):1385-96.

32. Alves KAP. Percepção de risco da infecção HIV entre adolescentes grávidas no Distrito Federal [Dissertação de mestrado]. [Brasília]: Faculdade de Ciência da Saúde, Universidade de Brasília; 2010.

33. Prata N, Morris L, Mazive E, Vahidnia F, Stehr M. Relationship between HIV risk perception and condom use: evidence from a population-based survey in Mozambique. Int Fam Plan Perspect. 2006; 32(4): 192-200.

34. Praça NS, Latorre MRDO, Hearst N. Fatores associados à percepção de risco de infecção pelo HIV por puérperas internadas. Rev Saude Publica. 2003; 37(5): 543-51.

35. Ferreira MP. Conhecimento e percepção de risco sobre o HIV/aids: um perfil da população brasileira no ano de 1998. Cad Saude Publica. 2003; 19 Suppl 2: 213-22. 
36. Camargo BV, Botelho LJ. Aids, sexualidade e atitudes de adolescentes sobre proteção contra o HIV. Rev Saude Publica 2007; 41(1):61-8.

37. Do M, Meekers D. Multiple sex partners and perceived risk of HIV infection in Zambia: attitudinal determinants and gender differences. AIDS Care. 2009; 21(10): 1211-21. 